November 1983

\title{
DISCLAIMER
}

\section{Foam Drainage}

\begin{abstract}
This report was prepared as an account of work sponsored by an agency of the United States Government. Neither the United States Government nor any agency thereof, nor any of their employees, makes any warranty, express or implied, or assumes any legal liability or responsibility for the accuracy, completeness, or usefulness of any information, apparatus, product, or process disclosed, or represents that its use would not infringe privately owned rights. Reference herein to any specific commercial product, process, or service by trade name, trademark, manufacturer, or otherwise does not necessarily constitute or imply its endorsement, recommendation, or favoring by the United States Government or any agency thereof. The views and opinions of authors expressed berein do not necessarily state or reflect those of the United States Government or any agency thereof.
\end{abstract}

\author{
Andrew M. Kraynik
}

\section{Prepared by}

Sandia National Laboratories

Albuquerque, New Mexico 87185 and Livermore, California 94550

for the United States Department of Energy

under Contract DE-AC04-76DPO0789

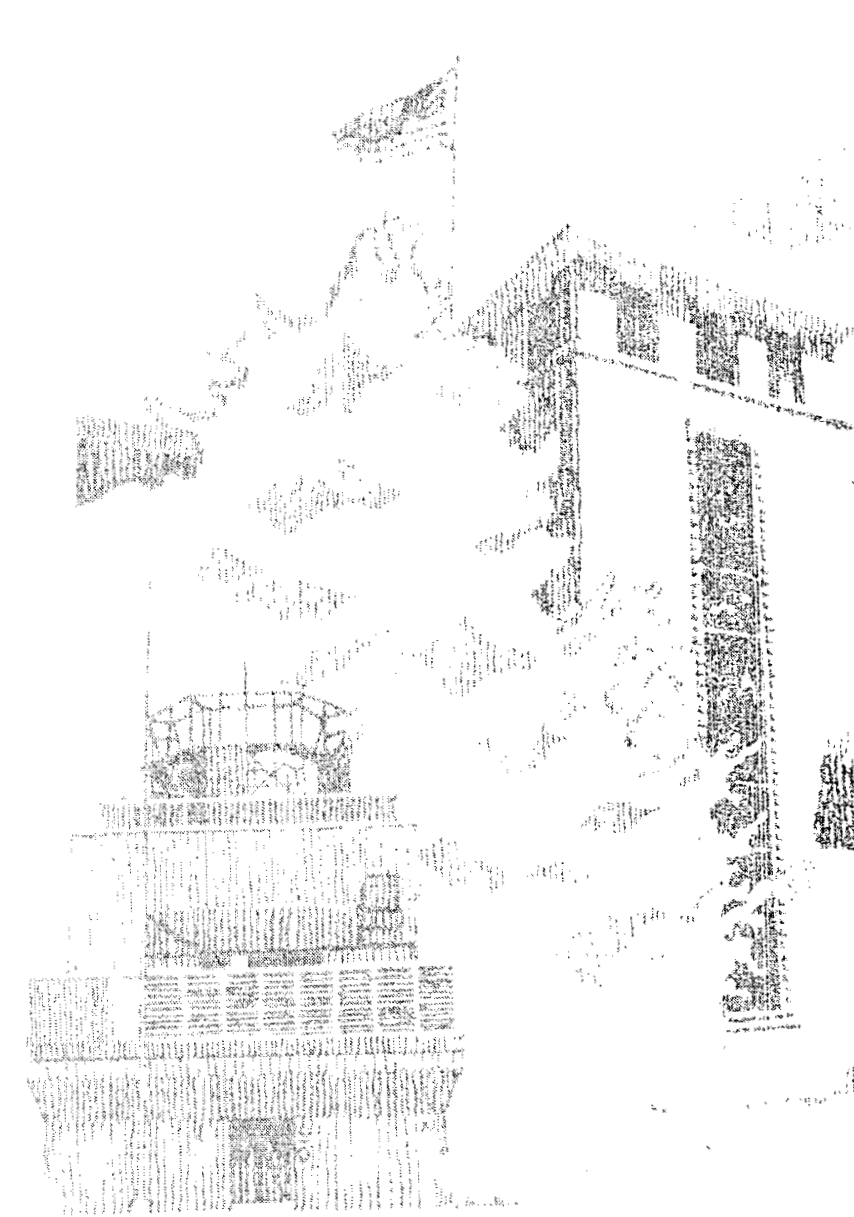


Issued by Sandia National Laboratories, operated for the United States Department of Energy by Sandia Corporation.

NOTICE: This report was prepared as an account of work sponsored by an agency of the United States Government. Neither the United States Government nor any agency thereof, nor any of their employees, nor any of their contractors, subcontractors, or their employees, makes any warranty, express or implied, or assumes any legal liability or responsibility for the accuracy, completeness, or usefulness of any information, apparatus, product, or process disclosed, or represents that its use would not infringe privately or process disclosed, or represents that its use would not infringe privately
owned rights. Reference herein to any specific commercial product, process, or service by trade name, trademark, manufacturer, or otherwise, does not necessarily constitute or imply its endorsement, recommendation, or favoring by the United States Government, any agency thereof or any of their contractors or subcontractors. The views and opinions expressed herein do not necessarily state or reflect those of the United States Government, any agency thereof or any of their contractors or subcontractors.

Printed in the United States of America Available from

National Technical Information Service

U.S. Department of Commerce

5285 Port Royal Road

Springfield, VA 22161

NTIS price codes

Printed copy: A03

Microfiche copy: A01 


\section{DISCLAIMER}

This report was prepared as an account of work sponsored by an agency of the United States Government. Neither the United States Government nor any agency Thereof, nor any of their employees, makes any warranty, express or implied, or assumes any legal liability or responsibility for the accuracy, completeness, or usefulness of any information, apparatus, product, or process disclosed, or represents that its use would not infringe privately owned rights. Reference herein to any specific commercial product, process, or service by trade name, trademark, manufacturer, or otherwise does not necessarily constitute or imply its endorsement, recommendation, or favoring by the United States Government or any agency thereof. The views and opinions of authors expressed herein do not necessarily state or reflect those of the United States Government or any agency thereof. 


\section{DISCLAIMER}

Portions of this document may be illegible in electronic image products. Images are produced from the best available original document. 
FOAM DRAINAGE *

A. M. Kraynik, Division 1813

Sandia National Laboratories

Albuquerque, NM 87185

\section{ABSTRACT}

Transient drainage from a column of persistent foam has been analyzed theoretically. Gravity-driven flow was assumed to occur through an interconnected network of plateau borders that define the edges of foam cells taken to be regular pentagonal dodecahedrons. A small liquid volume fraction and monodisperse cell size distribution were assumed. In the basic model, it is assumed that all liquid is contained in Plateau borders that are bounded by rigid gas-liquid interfaces. The predicted half life, the time required for one half of the liquid to drain from the foam, is inversely proportional to the square of the cell diameter, illustrating the importance of foam structure in arainage. Liquid hold up in the films separating adjacent cells, nonuniform initial liquid volume fraction distribution and interfacial mobility are explored. Border suction due to reduced pressure in the Plateau borders provides a mechanism for film drainage. Simultaneous film drainage and flow through the plateau borders are analyzed. Sufficient conditions for neglecting film drainage kinetics are obtained. The results indicate that improved foam stability is related to small cells, liquid hold up in the films and slow film drainage kinetics.

*This work performed at Sandia National Laboratories supported by the U. S. Department of Energy under contract number DE-AC0 4-76DP00789. 


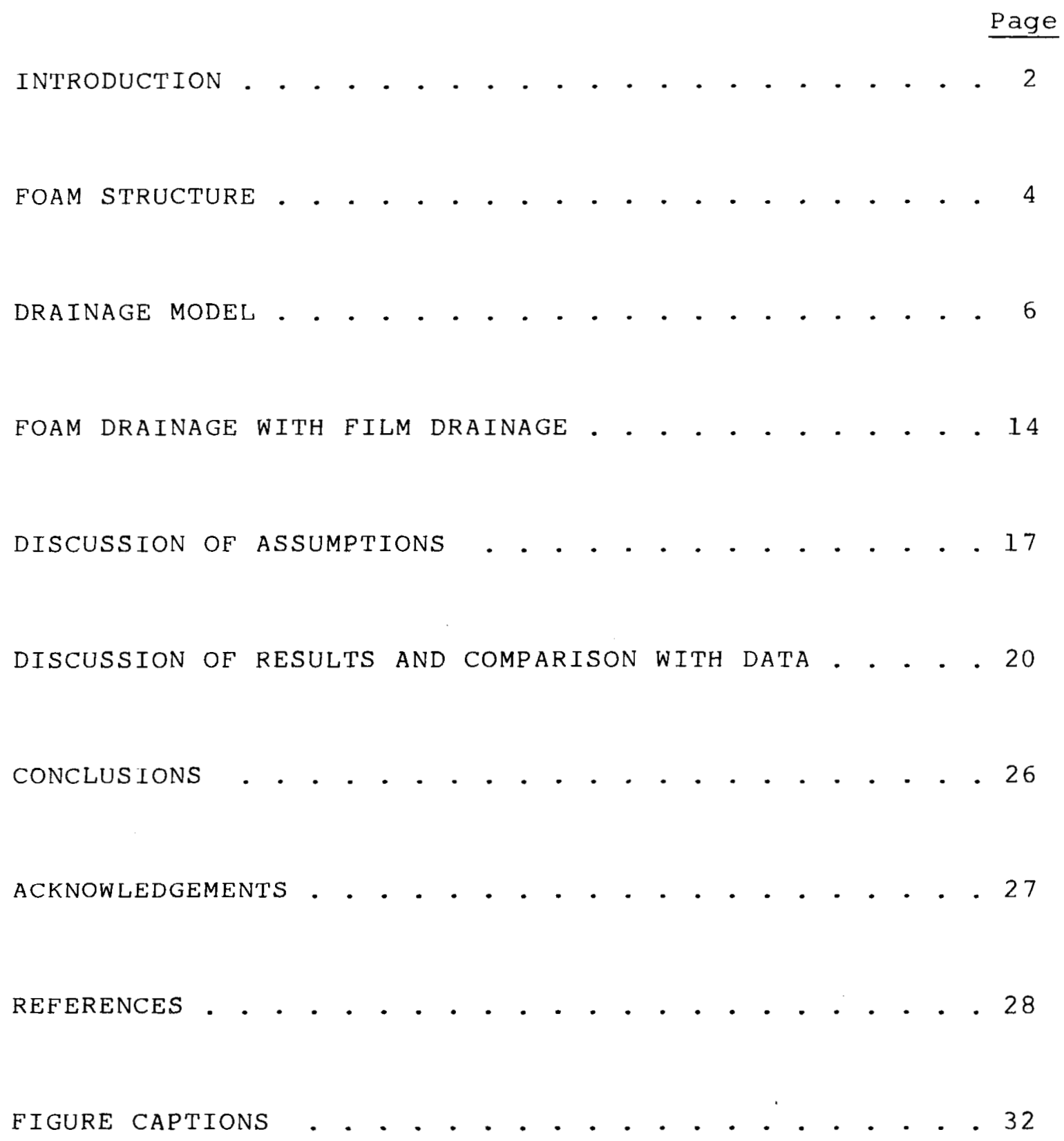




\section{INTRODUCTION}

Aqueous foams ranging in consistency from shaving cream to detergent soap suds are being developed for use in a wide variety of Sandia programs, e.g., Geothermal Drilling. The physical characteristics of aqueous foams make them excellent candidates for drilling fluids in geothermal formations (1). Rand and Montoya (2) have performed screening studies to identify surfactant systems with sufficient chemical stability to withstand the harsh geothermal environment. Rand (3) has developed an autoclave system to study the foam-forming ability of surfactant systems at high temperatures and pressures. Foam drainage, the time-dependent flow of liquid from a foam, was used to characterize "foam stability." A curious drainage phenomenon was observed during those tests. The drainage rate of foams made with the same surfactants and having the same liquid content by volume, decreased by over an order of magnitude as the pressure at which the foams were generated was increased by one hundred atmospheres. The effect proved to be an experimental artifact caused by a systematic decrease in the foam cell size with increasing generation pressure (4). The drainage study reported here was undertaken to explore the physical phenomena that affect foam drainage. However, we are not just interested in drainage for foam evaluation tests. The utility of foams in several applications depends upon their ability to suspend water in their internal structure and drainage is a direct measure of the "density stability" of foams. These applications include the Safeguard Program where high expansion 
foams are being considered as access deterents. In Nuclear Emergency Search Team (NEST) applications, aqueous foams successfully mitigate shock waves from explosive detonations and reduce the dispersion of particulate debris (5). Foams have also been considered in the Nuclear Reactor Safety Program to control the combustion of hydrogen released in accidents involving nuclear reactors $(6)$.

We consider a foam to be a dispersion of gas in a continuous liquid phase that is typically the minor component by volume. The utility of a foam often depends upon its ability to resist change, say, in volume or liquid content. Two major mechanisms for change include film breakage and liquid drainage. Both can occur simultaneously and interact in complicated ways. Pure liquids make poor foams because their films readily break due to the absence of a sufficient stabilizing mechanism $(7,8)$. In practice, it is well known that very small amounts of surfactant give rise to stabilizing colloidal forces that impart a high degree of persistence to thin liquid films. Thus, the effects of film breakage, which include the volume change associated with gas loss and a shift in the bubble size distribution due to bubble coalescence, can be minimized. The bubble size distribution can also shift because of gas diffusion between cells (9). We will only be concerned with "pure drainage" where the complications due to film rupture and other physical processes that affect the cell structure are not considered. Bikerman (10) has reviewed several equations used to correlate 
foam drainage data. Most of them are empirical in nature and neglect important physical phenomena. Significant fundamental drainage studies have been directed towards the steady-state foam fractionation process (11-14), however, the results cannot be directly applied to our situation, transient drainage from a stationary column of foam.

\section{FOAM STRUCTURE}

The liquid content reveals much about foam character and has been used to classify them as kugelschaum or polyederschaum, depending upon whether the liquid content is large or small, respectively (8). The gaseous inclusions or cells of the relatively "wet" kugelschaum are approximately spherical in shape and are separated by thick liquid films. We will focus our attention on polyederschaum, "dry" foams for which the liquid volume fraction, $f$, is much less than 0.259, which corresponds to the interstitial volume fraction for uniform closest-packed spheres. Because of crowding, the cells resemble polyhedra separated by thin flat liquid films.

The liquid in a dry foam is contained in either the films that separate two adjacent cells or in the Plateau borders that are formed at the intersection of three films, as shown in Figure 1a. The pressure in the Plateau borders is smaller than that in the adjacent cells due to surface tension and the curvature of the gas-liquid interface. The pressure difference is given by the Laplace-Young equation,

$$
\Delta \mathrm{p}=\frac{\sigma}{r}
$$


where $\sigma$ is the surface tension and $r$ the radius of curvature of a Plateau border. This pressure difference is the driving force for border suction which tends to drain liquid from the films into the plateau borders. As the films drain and thin, they become more susceptible to rupture which leads to cell coalescence. We will only be concerned with highly persistent foams in which the films resist rupture. These occur when stabilizing colloidal forces due to the presence of surfactant at the gas-liquid interface balance destabilizing effects such as border suction. The equilibrium thickness of the films may be sufficiently small, on the order of a micron or less, to allow their liquid content to be neglected.

When the surface tension is uniform, mechanical equilibrium requires that three films meet at a Plateau border at angles of $120^{\circ}$ and that four Plateau borders meet with the tetrahedral angle of $109^{\circ} 28^{\prime}$. No regular polyhedron which is also space filling satisfies these geometric criteria for a foam cell exactly, however a regular pentagonal dodecahedron comes close. Detailed morphological studies of foams consisting of monodisperse cells (15) support an idealized three-dimensional structural model with regular pentagonal dodecahedra as repeating units. Assuming this geometry, one can relate the liquid volume fraction, $f$, of a monodisperse dry foam to various structural parameters by $(11,13,14)$,

$$
f=1.26\left(\frac{r}{d}\right)^{2}+3.30 \frac{\delta}{d}
$$


where $\delta$ is the uniform thickness of the pentagonal films, $d$ the diameter of a sphere whose volume is equal to that of the gasfilled cell, and $r$ the radius of curvature of the plateau borders which are assumed to be equivalent to the space between three mutually tangent cylinders of radius $r$. Equation 2 is consistent with the fact that the total volume of a persistent dry foam does not change substantially as liquid drains from it. The terms containing $r$ and $\delta$ represent the liquid volume fractions associated with the Plateau borders and films, respectively. This simple relationship is only valid when the volume of the plateau borders does not depend upon film thickness as in the simplified geometry of Figure $1 \mathrm{~b}$.

\section{DRAINAGE MODEL}

Early attempts to model foam drainage considered the flow through various arrays of parallel plates or capillary tubes $(16,17)$ which were not realistic representations of foam structure. Leonard and Lemlich (11) were the first to incorporate the dodecahedron model of cell morphology into foam drainage calculations. They assumed that drainage due to gravity was dominated by flow through an interconnected network of plateau borders and neglected gravitational flow through the films, which is valid when $\delta \ll r$. Fundamental to their analysis is the flow through an individual Plateau border which is considered to be a long channel with the uniform cross section shown in Figure la. The flow can be considered fully developed when the length of the Plateau border is much greater than its radius of curvature, which is always 
true when $f \ll 1$. Unlike previous investigators, Leonard and Lemlich did not assume that the "no-slip" boundary condition was valid at the gas-liquid interface bounding the Plateau borders. Since viscous shear stresses in the gas-filled cells can be neglected, additional physics were invoked to balance the shear stresses that arise when no slip is assumed. Leonard and Lemlich attributed a surface shear viscosity, $\mu_{S}$, to the gas-liquid interface and explored the role of interfacial mobility in foam drainage. Since their study addressed the steady-state counter-current flow associated with foam factionation, the final results do not apply directly to transient drainage from stationary columns of foam. Also, trial-and-error techniques are often required to apply their numerical results which were summarized in graphical form.

Barber and Hartland (18) studied foam collapse and derived an expression for foam drainage. They assumed that film rupture was the primary mechanism for foam collapse. We will discuss major qualitative differences between their results and ours.

The fundamental expression for liquid flow through a network of Plateau borders was first derived by Leonard and Lemlich (1I). Following them, we consider the flow through an individual Plateau border whose axis is oriented at angle $\theta$ with respect to the horizontal plane as shown in Figure 2. The velocity at the gasliquid interface is assumed to vanish only at the points where the Plateau border joins the films. The dynamics at the gasliquid interface are described by incorporating a surface shear viscosity into the interfacial boundary condition. The relative 
surface mobility can be expressed in terms of a dimensionless parameter, M, defined as follows

$$
M \equiv \frac{\mu r}{\mu_{S}} \text {. }
$$

The expression for $\bar{u}$, the average liquid velocity through the Plateau border, can be written in the following form

$$
\bar{u}=0.00327 \frac{\rho g \sin \theta r^{2} F(M)}{\mu}
$$

where $\rho$ is the liquid density, $\mu$ the liquid viscosity and $g$ the gravitational constant. The dimensionless function, $F(M)$, shown in Figure 3, represents the mobility of the gas-liquid interface. A "rigid" interfacial condition is approached when $M<10^{-1}$, say. Neglecting the film contribution to liquid volume fraction in Equation 2, the condition for rigidity becomes

$$
\frac{\mu f^{1 / 2} \mathrm{~d}}{\mu_{s}}<10^{-1}
$$

This inequality is satisfied for an aqueous foam with $\mu=10^{-2}$ Poise, $\mathrm{f}=10^{-2}, \mathrm{~d}<10^{-2} \mathrm{~cm}$ and a typical value for $\mu_{\mathrm{s}}$ of $10^{-4} \mathrm{~g} / \mathrm{sec}$, which illustrates that the rigid interface condition is experimentally accessible.

Assuming that any plateau border orientation is equally probable, the net flux of liquid through the foam is obtained by integrating the flux through an arbitrary plateau border over all possible orientations while accounting for the density of Plateau borders,

$$
Q=\int_{0}^{\pi / 2} 1.26\left(\frac{r}{d}\right)^{2} \bar{u} \sin \theta \cos \theta d \theta
$$


to obtain,

$$
Q=0.00137 \frac{\rho g r^{4} F(M)}{\mu d^{2}} .
$$

As discussed by Leonard and Lemlich in an important footnote (11), the flow through a Plateau border imbedded in a foam network can be represented by Equation 4, which applies to an isolated Plateau border with no imposed axial pressure gradient, since the mass and momentum balances at the junction of four plateau borders are automatically satisfied because of the four-way symmetry.

The equations that govern transient drainage from a stationary column of foam are derived by considering a mass balance for the Plateau borders in the differential volume element $A_{C} d z$ in Eigure 4 (18),

$$
\frac{\partial}{\partial t}\left(\frac{1.26 r^{2}}{d^{2}}\right)+\frac{\partial Q}{\partial z}=V \text {. }
$$

The flux expression in Equation 7 is assumed to apply during transients where the radius of curvature of the Plateau borders may be slowly changing. $V$ is the volumetric flow rate of liquid draining from the films into the plateau borders per unit volume of foam. We will first consider solutions of Equation 8 for cases where $V$ equals zero, $i . e$. where the dynamics of film drainage can be neglected.

\section{FOAM DRAINAGE FOR NEGLIGIBLE FILM DRAINAGE}

When the dynamics of film thinning due to border suction are sufficiently fast, the macroscopic drainage rate from persistent 
foams is determined by gravity-driven flow through an interconnected network of plateau borders. The conditions required to neglect film drainage will be explored in the next section. Introducing dimensionless variables, Equation 2 becomes

$$
\frac{f}{\langle f\rangle}=U+D
$$

where

$$
u=\frac{1.26 r^{2}}{\langle f\rangle d^{2}}
$$

and

$$
D=\frac{3.30 \delta}{\langle f\rangle d}
$$

$\langle f\rangle$ is the average initial liquid volume fraction in the foam column. $U$ and $D$ represent the liquid content associated with the Plateau borders and films, respectively. Setting V=0, substituting for $Q$ and introducing dimensionless variables, Equation 8 becomes

$$
\frac{\partial U}{\partial \tau}+\frac{1}{2} \frac{\partial}{\partial \xi}\left(F U^{2}\right)=0
$$

where

$$
\begin{aligned}
\tau & =t / t_{O} \\
t_{0} & =\frac{580 \mu H}{\rho g d^{2}\langle f\rangle}
\end{aligned}
$$

and

$$
\xi=\mathrm{z} / \mathrm{H} \text {. }
$$

$\mathrm{H}$ is the height of the foam column. We will first derive the simplest possible model of foam drainage which will be referred to as the "basic model." This model will incorporate the largest number of simplifying assumptions and therefore contain the fewest parameters. Specifically, we will assume: 
1) rigid gas-liquid interfaces, i.e. $F(M)=1$,

2) uniform initial liquid volume fraction distribution,

3) negligible liquid hold-up in the films, $D=0$.

With these assumptions, Equation 10 reduces to

$$
\frac{\partial U}{\partial \tau}+U \frac{\partial U}{\partial \xi}=0
$$

The appropriate inital and boundary conditions are

$$
U(\xi, 0)=1 \quad \text { for } 0 \leq \xi \leq 1
$$

and

$$
U(\xi, \tau)=0 \quad \text { for } \xi<0
$$

The boundary condition expresses the fact that no liquid enters the top of the foam column. Applying the method of characteristics the solution to Equations 11 and 12 is

$$
\mathrm{U}=\frac{\xi}{\tau} \quad \text { for } \frac{\xi}{\tau}<1
$$

and

$$
U=1 \quad \text { for } \frac{\xi}{\tau} \geq 1 \text {. }
$$

This result represents the time-dependent liquid volume fraction distribution in the foam column. The time-dependent accumulation of liquid that has drained from the foam is given by

$$
W(\tau)=A_{C} \int_{0}^{\tau} Q(\xi=1) d \tau
$$

where $W(\tau)$ represents the volume of liquid and $A_{C}$ is the crosssectional area of the column. After substituting for $Q(\xi=1)$, Equation 14 can be written in the following dimensionless form 


$$
A(\tau)=\frac{1}{2} \int_{0}^{\tau} F(M)\{U(1, \tau)\}^{2} d \tau
$$

where $A(\tau)=W(\tau) / W_{O}$ and $W_{O}$ is the total volume of liquid initially contained in the foam. Substituting for $U(1, \tau)$ and integrating with $F(M)=1$ yields

$$
A=\frac{\tau}{2} \quad \text { for } \tau \leq 1
$$

and

$$
A=1-\frac{2}{\tau} \quad \text { for } \tau>1
$$

The predictions of the basic model are shown in Figures 5 and 6 . It is relatively straightforward to incorporate a nonuniform initial liquid volume fraction distribution and liquid hold up in the films into a drainage model. For illustration, we assume that $D$ is equal to a fixed parameter, $D_{0}$, which can be related to the equilibrium thickness of a fully-drained film, and that $U(\xi, 0)$ is a linear function of position only,

$$
U(\xi, 0)=X\left\{U_{0}+2\left(1-U_{O}\right) \xi\right\}
$$

where

$$
\mathrm{X}=1-\mathrm{D}_{0}
$$

The following solutions for $U(\xi, \tau)$ are obtained

$$
\mathrm{U}=\frac{\xi}{\tau} \quad \text { for } \frac{\xi}{\tau}<\mathrm{XU}_{\mathrm{O}}
$$

and

$$
U=\frac{2 X\left(1-U_{0}\right) \xi+U_{0} X}{2 X\left(1-U_{0}\right) \tau+1} \quad \text { for } \frac{\xi}{\tau} \geq X U_{0}
$$


The liquid accumulation is given by

$$
A=\frac{\left(2-U_{0}\right)^{2} \tau X^{2}}{4\left(1-U_{0}\right) \tau X+2} \quad \text { for } \tau \leq \frac{1}{U_{0} X}
$$

and

$$
A=X-\frac{1}{2 \tau} \quad \text { for } \tau>\frac{1}{U_{0} X} \text {. }
$$

We note that

$$
\lim _{\tau \rightarrow \infty} A=X=1-D_{0}
$$

because liquid that remains in the films cannot drain from the foam. The drainage curves for various values of $\mathrm{X}$ and $\mathrm{U}_{\mathrm{O}}$ are included as Figures 7 and 8 .

Since $F(M)$ is a tabulated fuction, complete analytical solutions to Equation 10 cannot be obtained when $r$ varies spatially. However, drainage curves for short times can be calculated when the initial distribution of liquid in the Plateau borders is uniform since $F(M)$ does not vary spatially near the bottom of the column. The initial condition

$$
U(\xi, 0)=x \quad \text { for } 0 \leq \xi \leq 1
$$

results in the following solution

$$
\mathrm{U}(\xi, \tau)=\mathrm{X} \quad \text { for } \frac{\xi}{\tau} \geq \mathrm{XF}_{\mathrm{O}}
$$

and drainage curve

$$
A=\frac{X^{2} F_{0} \tau}{2} \quad \text { for } \tau \leq \frac{1}{X_{0}}
$$


where $F_{O}$ is the mobility evaluated at the initial condition and requires knowledge of the surface shear viscosity

\section{FOAM DRAINAGE WITH FILM DRAINAGE}

The role of film drainage kinetics in foam drainage was first explored by Hartland and Barber (13) and pursued in later studies (14). An explicit expression for $V$ is required. We follow Hartland and Barber and assume that film drainage can be modeled as axisymmetric squeezing flow between parallel circular disks. The pressure difference between the gas-filled cells and the Plateau borders, acting upon the surfaces of the films, provides the driving force for film drainage. In their original work, Hartland and Barber employed a modified version of the StefanReynolds' equation to represent the rate of film thinning

$$
\frac{d \delta}{d t}=-29.1 \frac{\delta^{3} \sigma}{n^{2} \mu d^{2} r}
$$

The area of a circular film has been equated to that of a pentagonal film associated with the regular dodecahedron. The parameter, $n$, representing the number of immobile film surfaces, was included to allow for interfacial mobility. In a later study of drainage in planar liquid films, Barber and Hartland (19) employed surface shear and dilatational viscosities to describe the interfacial boundary condition. We have used their results to relate surface mobility to the following dimensionless group,

$$
\mathrm{M}_{\mathrm{F}} \equiv \frac{\mu \mathrm{d}^{2}}{\eta \delta}
$$


where $\eta$ a linear combination of surface shear and dilatational viscosities. The following asymptotic expressions for film thinning can be obtained,

$$
\frac{\mathrm{d} \delta}{\mathrm{dt}}=-7.29 \frac{\delta^{3} \sigma}{\mu \mathrm{d}^{2} \mathrm{r}} \quad \text { when } \mathrm{M}_{\mathrm{F}} \ll I
$$

which corresponds to the rigid film limit described by the stefanReynolds' equation (with $n=2$ ), and

$$
\frac{d \delta}{d t}=-\frac{\delta^{2} \sigma}{2 \eta r} \quad \text { when } M_{F}>1
$$

which corresponds to the mobile film limit where thinning is controlled by the surface viscosities and not the bulk viscosity. The results in Equations 26 and 27 show that, in general, the surface mobility cannot be represented by a fixed parameter like $\mathrm{n}$ in Equation 24 since the films can change from rigid to mobile as they thin and $M_{F}$ increases. Note the striking contrast in the flow behavior through plateau borders and in films as their dimensions change during drainage. Plateau borders become more rigid as $r$ decreases since $M$ decreases. However, the films become more mobile as $\delta$ decreases because $M_{F}$ increases. Only one length scale, $r$, determines the mobility of the plateau borders. Two lengths influence the mobility of the films, $\delta$ and their radius which is related to $d$.

Using Equations 26 and 27, we can obtain explicit expressions for $V$, the rate of liquid drainage from the films into the plateau borders per unit volume of foam. In the rigid film limit, 


$$
V=\frac{24 \sigma \delta^{3}}{\mu d^{3} r} \quad \text { when } M_{F} \ll 1
$$

while in the mobile film limit,

$$
\mathrm{V}=1.65 \frac{\sigma \delta^{2}}{\eta \mathrm{dr}} \quad \text { when } \mathrm{M}_{\mathrm{F}} \gg 1
$$

We now derive a set of coupled first order partial differential equations that describe drainage when all gas-liquid interfaces are considered rigid. Introducing dimensionless variables into Equations 8, 26 and 28 and combining yields

$$
\frac{\partial U}{\partial \tau}+U \frac{\partial U}{\partial \xi}=2 F_{R} \frac{D^{3}}{U^{1 / 2}}
$$

and

$$
\frac{\partial D}{\partial \tau}=-2 F_{R} \frac{D^{3}}{U^{1 / 2}}
$$

where

$$
F_{R} \equiv \frac{217\langle f\rangle 1 / 2 \sigma H}{\rho g d^{3}} \text {. }
$$

The dimensionless parameter, $F_{R}$, can be considered a ratio of two characteristic times that govern arainage through the Plateau borders and thinning of the films. We now consider the case where all of the liquid is initially contained in the films. The following initial and boundary conditions apply,

$$
\begin{array}{cr}
U(\xi, 0)=0 & \text { for } 0 \leq \xi \leq 1 \\
D(\xi, 0)=1 & \text { for } 0 \leq \xi \leq 1 \\
D(\xi, \tau)=U(\xi, \tau)=0 & \text { for } \xi<0 .
\end{array}
$$


Numerical techniques developed by Treadway (20) were used to solve Equations 30-32. The drainage curves for various values of $F_{R}$ are included in Figure 9. These results show that film drainage kinetics can be neglected when $F_{R}>10^{4}$. This criterion is conservative since film drainage is slowest when all interfaces are rigid.

Assuming rigid Plateau borders and mobile films, Equations 8, 27 and 29 can be combined to obtain

$$
\frac{\partial U}{\partial \tau}+U \frac{\partial U}{\partial \xi}=2 F_{M} \frac{D^{2}}{U}
$$

and

$$
\frac{\partial D}{\partial \tau}=-2 F_{M} \frac{D^{3}}{U}
$$

where

$$
F_{M} \equiv \frac{49 \sigma \mu H}{\eta d^{2}<f>1 / 2 \rho g} .
$$

$F_{M}$ is the counterpart of $F_{R}$ for mobile film drainage. The initial and boundary conditions in Equation 32 were usea to solve Equations 33 and 34. Drainage curves for various $F_{M}$ are shown in Figure 10. The kinetics of mobile film drainage can be neglected when $F_{M}>10^{3}$.

\section{DISCUSSION OF ASSUMPTIONS}

The treatment of boundary conditions at the gas-iquid interface is fundamental to any drainage analysis. Our use of surface viscosity to describe the interfacial mobility should not 
be viewed as exact because the Boussinesq surface fluid is a relatively simple model of the interfacial region (21). This constitutive dilemma is analogous to that faced in any nonlinear rheological analysis. Unfortunately, any comparison between foam drainage theory and experiment will probably be confronted with large uncertainties related to the interfacial regions. Visual observation of the complicated circulation patterns in an isolated soap film provides strong evidence of the approximate nature of our analysis.

Consider the flow through an individual plateau border. Our results assume the channel geometry shown in Figure 1 for which the contact angle between the films and Plateau borders is zero. Finite contact angles between films and their borders have been measured (22). When the curvature of a two-dimensional plateau border is constant, its cross section would vary as shown in Figure 1l, assuming that the sign of the principal curvature does not change. The average velocity through a rigid plateau border would vary from

$$
\bar{u}=0.0203 \frac{A_{p} \rho g \sin \theta}{\mu}
$$

when the contact angle is zero to

$$
\bar{u}=0.0289 \frac{A_{p} \rho g \sin \theta}{\mu}
$$

for an equilateral triangle (23) when the contact angle is $30^{\circ}$. $A_{p}$ represents the cross-sectional area of a Plateau border. The flow rate for equal $A_{p}$ would be about 42 percent greater for a triangular channel than assumed in our model. The effect 
of a finite contact angle on flow through the Plateau borders is small when compared to the potential reduction in border suction which decreases with increasing contact angle and vanishes along with the mean curvature for the equilateral triangle. This is especially significant for film drainage calculations which rely upon border suction as the sole driving force.

Our treatment of film drainage dynamics is based upon several common assumptions $(13,14)$. First, forces of a colloidal nature which compete in any way with border suction are neglected. This is justified in those cases where films thin sufficiently for their liquid hold up to be neglected before colloidal effects become important. Our results do not apply when film drainage is slow and liquid hold up in the films is large. A second approximation involves the film shape which is assumed to be planar. Consider the rigid-film drainage limit where the Stefan-Reynolds' equation is assumed to apply. Shear stresses in the film result in a radial pressure distribution. Since uniform pressure is assumed in the gas-filled cells, a pressure jump must exist across the gas-liquid interface. The pressure jump aistribution associated with film drainage is given by

$$
\mathrm{P}_{\text {film }}-\mathrm{P}_{\text {gas cell }}=\frac{\sigma}{\mathrm{r}}\left[1-2\left(\frac{\hat{r}}{\mathrm{R}}\right)^{2}\right]
$$

where $r$ is the radial distance from the midpoint of a film of radius $R$. The jump at the film midpoint is equal in magnitude but opposite in sign to that in the Plateau borders. Assuming 
uniform surface tension, this implies that the magnitude of the mean curvature at the film midpoint is the same as that in the Plateau borders, which is inconsistent with the assumption of planar films. The dimpling implied by Equation 37 is well known but only approximate numerical solutions for nonplanar film drainage are available (24). Their use is not justified here in view of the other uncertainties associated with drainage analysis.

\section{DISCUSSION OF RESULTS AND COMPARISON WITH DATA}

The basic model predicts a constant drainage rate for times less than $t_{0}$ and a continually decreasing drainage rate for times greater than $t_{0}$, which is defined in Equation 10 . In the basic model, $t_{0}$ corresponds to the time of arrival of the liquidvolume-fraction rarefaction wave at the base of the foam column. The solution in Equation 13, which is shown in Figure 5, represents a simple model of the liquid distribution in the foam. This information is important in applications like NEST where the usefulness of foam depends upon its internal liquid distribution. In the basic model, $t_{0}$ also corresponds to the foam half life which is the time required for half of the original liquid to drain. The half life is a useful parameter for characterizing foams. The basic model indicates the minimum number of parameters required to interpret half-life data. The half life is not a physical property since it depends upon the foam depth, a characteristic of the experimental configuration.

The liquid volume fraction or its equivalent is a routinely measured characteristic of foam structure that effects arainage. 
We feel that results which describe the role of foam structure in drainage are a major consequence of our modelling effort. The importance of cell size has been discussed elsewhere $(10,11$, $13,14,17,18)$ and is emphasized here by the fact that to is inversely proportional to the square of the cell diameter. Rand and Kraynik (4) recently used this fact to show how experimental artifacts related to foam generation technique could explain curious foam drainage results.

The basic model has provided guidance to the NEST program by predicting the improved drainage characteristics of fine-celled foams. This lead to the design of improved foam generators. It is interesting to note that a model for foam collapse obtained by Barber and Hartland (18) predicts the opposite effect of cell size. They assumed that bubble coalescence was the primary mechanism for foam collapse. Their results suggest that the initial foam drainage rate is proportional to $d^{-9 / 5}$ while the basic model predicts $d^{2}$. This descrepancy is due entirely to different assumptions concerning film stability. We assume that the films are stable to rupture regardless of how thin they become. Under those circumstances flow through the Plateau borders determines the drainage rate. Barber and Harland assumed that all films drain according to the Stefan-Reynolds' equation with border suction unopposed by any stabilizing forces. Film collapse was assumed to occur at some critical film thickness. Under those circumstances small cells promote film rupture because border suction is stronger and the films are initially thinner. 
Drainage curves that fit the time dependence predicted by Equation 16 and shown in Figure 6 have been reported by Haas (17). In fact, Haas derived drainage results which were similar to ours but contained an adjustable parameter because he considered the flow through a system of equivalent capillaries. The experimental details were sufficient to permit the comparison between measured and calculated values for $t_{0}$ which are contained in Table I. The experimental half lives are about an order of magnitude smaller than those predicted by the basic model. The comparison is not completely fair because the initial liquid volume fractions in Haas' experinents varied from 0.147 to 0.470 which is too large to consider his foams dry. The plateau borders certainly did not resemble two-dimensional channels as assumed in our analysis. It is highly likely that interfacial mobility contributes significantly to the discrepancies in Table I since the calculated values for to assume rigid interfaces. It is worth mentioning that Haas' foams, like most real systens, were not monodisperse. The reported cell diameters represent average values. Any experimental uncertainty associated with cell size determination is magnified by the squared dependence of $t_{0}$ on $d$.

Haas' experimental technique warrants discussion because it eliminates some of the artifacts which complicate the interpretation of drainage data. Eirst, his "initial" foam configurations were actually obtained by running foam fractionation columns at steady state. This procedure eliminates any nonuniformities in the initial liquid-volume-fraction distribution associated with the time required to fill the column with foam. It also reduces 
the effects of transient film drainage since the films present at the beginning of the transient experiment have significant average lifetimes and will have drained to some degree. Haas measured drainage by observing the rising liquid level at the base of the foam column. This technique is less sensitive for very dry foams which contain little liquid so it is common practice to employ a funnel-like collection device to direct liquid into a graduated cylinder to facilitate volume measurement. However, the observed drainage is certainly affected by artifacts due to liquid flow along the inclined solid surfaces of the collection device. This and related phenomena are probably responsible for the fact that "no" drainage is observed at the beginning of some drainage experiments for times up to several minutes (25).

For mobile interfaces, $F$ in Equation 10 depends upon $U$ and the drainage curves will differ from Equation 16. However, as shown by Equation 23, the drainage curve can still display a linear region which can be used to estimate the mobility parameter $F_{O}$ when $X$, the Eraction of liquid initially contained in the plateau borders, is known.

It is not uncommon for the drainage rate to continually change during an experiment. This can be related to liquid collection technique but other causes are possible, eg. a nonuniform initial liquid-volume-fraction distribution. Refer to Equation 19 and Figure 7, which apply for linear initial liquid-volume-fraction distributions. The drainage rate continually decreases when the initial liquid distribution is bottom heavy $\left(U_{0}<1\right)$ and goes 
through a maximum when it is top heavy $\left(U_{O}>1\right)$. The initial liquid distribution in the foam column strongly depends upon the foam generation technique. In fact prominent drainage rate maxima in one study were apparently caused by a top-heavy liquid distribution that was related to the foam generation technique (26). Film drainage affects foam drainge by controlling the rate of liquid delivery into the Plateau borders. Obviously, any liquid that remains in the fully-drained films of a persistent foam cannot drain from the foam (see Equation 20). This mechanism may contribute to the remarkable drainage statiblity of high-expansion foams made from stabilized surfactant systems developed by Rand (27). The surfactant solutions are prepared from concentrates and therefore are referred to as AFC (aqueous foam concentrate) systems.

Our analysis indicates that film drainage kinetics may also influence foam drainage in AFC systems. The results shown in Figure 9 allow us to estimate the importance of film arainage kinetics in foam drainage. When $F_{R}$ is greater than $10^{4}$, film drainage occurs fast relative to flow through the Plateau borders and does not influence foam drainage. This criterion is sufficient for neglecting film drainage kinetics but not necessary. Interfacial mobility will increase film drainage rates beyond those related to the results of Figure 9 which assume rigid interfaces. Additional information on interfacial mobility may be needed to clarify the importance of film drainage kinetics. Film drainage becomes rate determining when the interfaces are rigid and $F_{R} \ll 10^{4}$ by starving the Plateau borders and thereby reducing flow through them. 
Film drainage introduces another physical property, $\sigma$, the surface tension into consideration. Large surface tensions are destabilizing in the sense that they cause faster film drainage by increasing border suction. This may be of little practical importance because of the limited range of surface tensions available for surfactant systems that produce persistent foams.

The influence of foarn structure on the importance of film drainage is demonstrated by example. Consider two foams that differ in liquid volume fraction and cell size alone. One, like shaving cream, has small cells, $d=0.01 \mathrm{~cm}$, and relatively large liquid content, $f=0.05$. The other, a so-called high-expansion foam, has large cells, $d=1 \mathrm{~cm}$, and is very dry, $f=0.002$. The remaining parameter values are assumed: $\sigma=50$ dynes $/ \mathrm{cm}, H=100 \mathrm{~cm}, \rho=1$ $\mathrm{g} / \mathrm{cm}^{3}$ and $\mathrm{g}=980 \mathrm{~cm} / \mathrm{sec}^{2}$. For the fine-celled foam $F_{\mathrm{R}}$ is greater than $10^{8}$ so film drainage does not affect foam drainage rates. However, for the high-expansion foam, $F_{R}$ is about 50, so film drainage kinetics may be rate-determining for sufficiently rigid film interfaces. Aubert (28) has used the "Cup of Tea" technique developed by Krieg et.al. (29) to measure the interfacial shear viscosity of several aqueous surfactant solutions. Preliminary results indicate that AFC systems possess surface viscosities much larger than those of non-stabilized systems, which supports a stabilizing film-drainage kinetic mechanism. The results for the fine-celled foam indicate that film drainage kinetics cannot be rate determining in those systems. In fact, fine-celled foams made with AFC surfactant systems do not significantly outperform those made with commercial surfactant solutions of comparable 
viscosity in drainage tests. This observation is consistent with our kinetic stabilization mechanism for high-expansion foams.

The films are mobile when $M_{F} \gg 1$ and our analysis indicates that mobile film drainage is rate determining when

$$
F_{M}=\frac{49 \sigma H f^{1 / 2} M_{F}}{\rho g d^{3}}<1 .
$$

We have used the fact that $\frac{\delta}{d} \approx f$ when the films are nearly full. With $\mathrm{H}=100 \mathrm{~cm}, \mathrm{~d}=1 \mathrm{~cm}, \sigma=50$ dynes $/ \mathrm{cm}, \rho=1 \mathrm{~g} / \mathrm{cm}^{3}$ and $g=980 \mathrm{~cm} / \mathrm{sec}^{2}$, this criterion becomes

$$
\mathrm{M}_{\mathrm{F}^{\mathrm{f}}} \mathrm{I}^{1 / 2}<10^{-2}
$$

It is difficult to make foams with $f<10^{-4}$ so this condition is hard to satisfy in practice.

\section{CONCLUSIONS}

Foam drainage involves many complicated phenomena under the best of circumstances. The basic model presented here contains no empirical parameters and provides a simple description of transient drainage from a column of persistent foam. We analyze the flow through an interconnected network of plateau borders that define the edges of cells assumed to be regular pentagonal dodecahedrons. The derivation is based upon the following simplifying assumptions:

1. The foam is persistent, i.e., the films are stable and do not rupture during drainage.

2. The cell-size distribution is monodisperse and does not change due to intercellular gas diffusion. 
3. The foam is dry, i.e., the liquid volume fraction is less than 0.1 .

4. The gas-liquid interfaces of the plateau borders are rigid and therefore the no-slip boundary condition is used.

5. Liquid hold up in the films is negligible because the fully-drained films are thin.

6. The initial liquid-volume-fraction distribution is uniform.

7. The film drainage kinetics are fast and therefore are not rate determining.

These assumptions are obviously restrictive but the basic model provides a logical basis for comparison with experimental data. Each of the last four assumptions is relaxed in further analysis and their influence explored.

Many literature drainage studies do not provide sufficient information for comparison with theory. Our model provides guidance for the design of drainage experiments by indicating important paraneter dependence. The relationship between the physical structure of a foam and drainage is illuminating. The structural parameters studied include: liquid volume fraction, cell size, film thickness and liquid-volume-fraction distribution.

\section{ACKNOWLEDGEMENT}

I would like to thank A. H. Treadway of Sandia National Laboratories for developing the numerical methods employed here. 


\section{REFERENCES}

1. Pye, D. S. and Fischer, P. W., "Foam Drilling and Workover in High-Temperature Wells," U.S. Patent No. 4, 201,678 (1980).

2. Rand, P. B. and Montoya, O. J.., "Aqueous Foam Surfactants for Geothermal Drilling Fluids: I. Screening," SAND792036, Sandia National Laboratories, Albuquerque, NM (January $1980)$.

3. Private communication from P. B. Rand, Sandia National Laboratories (1982).

4. Rand, P. B. and Kraynik, A. M., "Drainage of Aqueous Eoams: Generation-Pressure and Cell-Size Effects," Soc. Pet. Eng. J., 23:1, 152-154, February (1983).

5. Griffiths, S. K., "Shock Wave Propagation in Aqueous Foams," SAND82-1482, Sandia National Laboratories, Albuquerque, NM (in preparation).

6. Baer, M. R., Griffiths, S. K. and Shepherd, J. E., "Hydrogen Combustion in Aqueous Foams," SAND82-0917, Sandia National Laboratories, Albuquerque, NM (September 1982).

7. Kitchener, J. A. and Cooper, C. F., "Current Concepts in the Theory of Foaming," Quarterly Reviews, 13:1, 71-97 (1959).

8. Adamson, A. W., Physical Chemistry of Surfaces, John Wiley, New York, NY $(197 \overline{6})$.

9. Lemlich, R., "Prediction of Changes in Bubble Size Distribution Due to Interbubble Gas Diffusion in Foam," Ind. Eng. Chem. Fund., 17:2, 89-93 (1978).

10. Bikerman, J. J., Foams, Springer-Verlag, New York, NY (1973).

11. Leonard, R. A. and Lemlich, R., "A Study of Interstitial Liquid Flow in Foam: Part $I$. Theoretical Model and Application to Foam Fractionation," A.I.Ch.E.J., 11:1, 18-25 (1965).

12. Ho, G. E. and Prince, R. G. H., "Characteristics of Cellular Foam on Perforated Plates," in Proceedings of Symposium on Bubbles and Foams, Nuremberg: Verein Deutscher Ingenieure, 79-89, (1971).

13. Hartland, S. and Barber, A. D., "A Model for a Cellular Foam," Trans. Inst. Chem. Eng., 52, 43-52 (1974).

14. Steiner, L., Hunkeler, R. and Hartland, S., "Behavior of Dynamic Cellular Foams," 55, 153-163 (1977). 
15. Matzke, E. B., "The Three-Dimensional Shape of Bubbles in Foam--An Analysis of the Role of Surface Forces in ThreeDimensional Cell Shape Determination," Amer. J. Botany, 33, 58-81 (1946).

16. Jacobi, W. M., Woodcock, K. E. and Grove Jr., C. S., "Theoretical Investigation of Foam Drainage," Ind. Eng. Chem., 48:11, 2046-2051 (1956).

17. Haas, P. A., "Engineering Development of a Foam Column for Countercurrent Surface-Liquid Extraction of Surface-Active Solutes," U.S. A.E.C. Tech. Rept. ORNL-3527, Oak Ridge National Laboratory, Oak Ridge, TN (June 1965).

18. Barber, A. D., and Hartland, S., "The Collapse of Cellular Foams," Trans. Inst. Chem. Eng.. 53, 106-111 (1975).

19. Barber, A. D. and Hartland, S., "The Effects of Surface Viscosity on the Axisymmetric Drainage of Planar Liquid Films," Can. J. Chem. Eng., 54, 279-284 (1976).

20. Private communication from A. H. Treadway, Sandia National Laboratories (1982).

21. Slattery, J.C. and Flumerfelt, R. W., "Interfacial Phenomena," in Handbook of Multiphase Systems (edited by G. Hetsroni), Hemisphere, Washington, D. C. (1980).

22. Princen, H. M., Aronson, M.P. and Moser, J. C., J. Colloid Interface Sci., 75, 246-270 (1980).

23. White, F. M., Viscous Fluid Flow, MCGraw-Hill, New York, NY, $123-125(1974)$.

24. Lin, Cheng-Yuan and slattery, J. C., "Thinning of a Liquid Film as a Small Drop or Bubble Approaches a Fluid-Fluid Interface," A.I.Ch.E.J., 28:5, 786-792 (1982).

25. Corrie, J. G., "Experimental Methods for the Study of FireFighting Foams," in Foams (edited by R. J. Akers), Academic Press, London, 195-21 $\overline{5}(1976)$.

26. Arbuzov, K. N. and Grebenshchikov, B. N., J. Phys. Chem. (U.S.S.R.), 10, 32 (1937).

27. Private communication from P. B. Rand, Sandia National Laboratories (1982).

28. Private communication from J. H. Aubert, Sandia National Laboratories (1983). 
29. Krieg, R. D., Son, J. E. and Flumerfelt, R. W., "A New Method for Surface Shear Viscosity Measurements: Decay of Surface Motions at a Rotated Gas-Liquid Interface," J. Colloid Interface sci., 79:1, 14-20 (1981). 
TABLE I

Comparison Between Half tives Predicted by the

Basic Model and the Experimental Data of Haas (17)

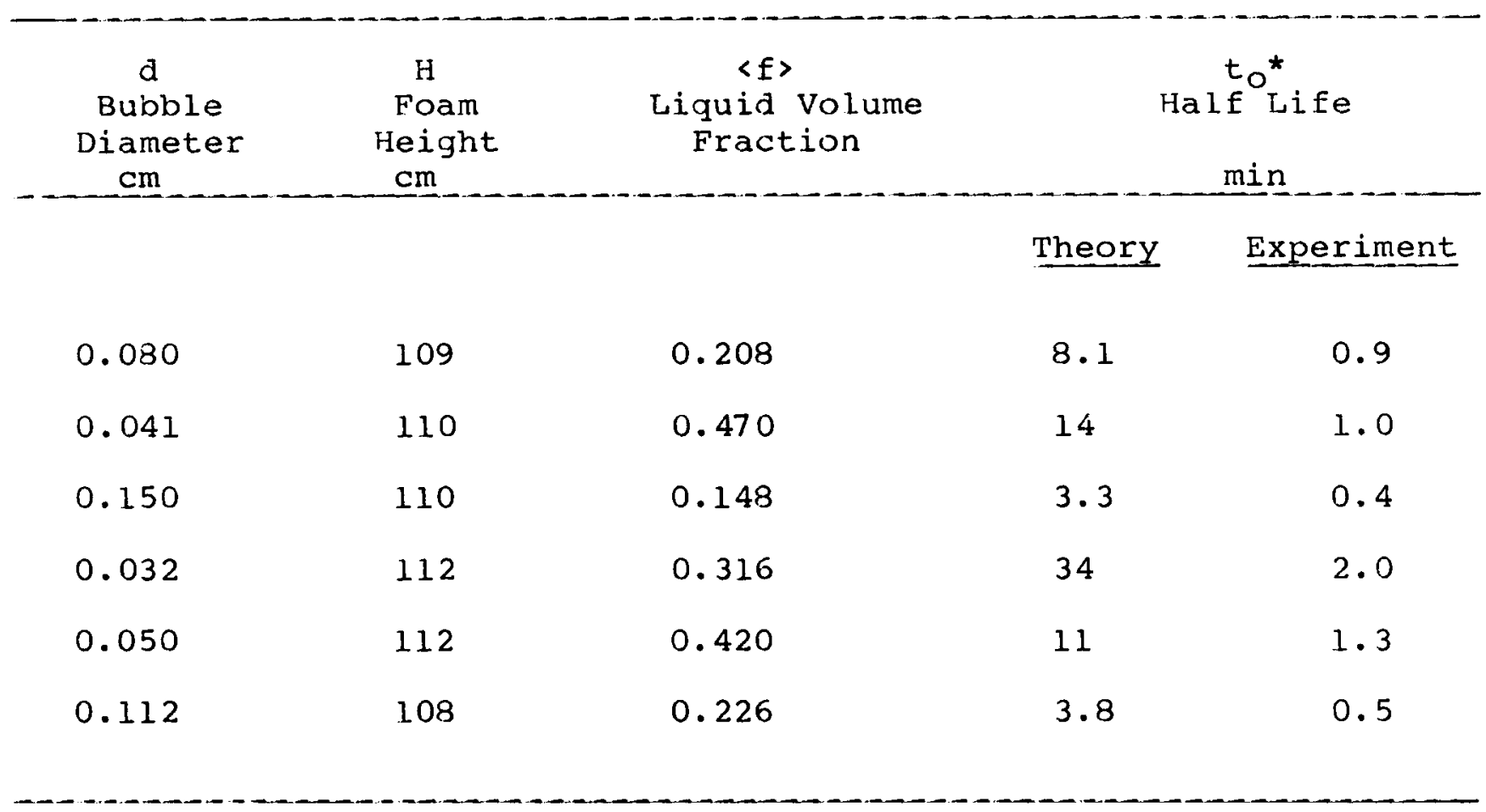

*Liquid viscosity was assumed to be 0.01 Poise.

Liquid density was assumed to be $1 \mathrm{~g} / \mathrm{cm}^{3}$. 
Figure 1. a) Schematic diagram showing, in cross section, the intersection of three films to form a Plateau border.

b) The idealized plateau border cross section used to calculate liquid content and flow.

Figure 2. The idealized Plateau border channel geometry assumed for flow calculations.

Figure 3. The mobility function used to relate flow through the Plateau borders to the mobility of the gas-liquid interfaces that bound them. $F(M)$ is obtained from the results of Leonard and Lemlich (11).

Figure 4. Schematic showing the foam column geometry assumed in our analysis.

Figure 5. Plot of the liquid volume fraction distribution predicted by the basic model during foam drainage. A liquid volume fraction rarefaction wave originates at the top of the column and progresses at constant speed to the bottom.

Figure 6. Drainage curve predicted by the basic model. The change from constant slope at a dimensionless time of unity corresponds to the arrival of the liquid volume fraction rarefaction wave at the base of the foam column.

Figure 7. Drainage curves corresponding to a nonuniform initial liquid volume fraction distribution which varies linearly with height. Ifiquid hold up in the films is neglected $(\mathrm{X}=1)$. $\mathrm{U}_{0}<1$ corresponds to a bottomheavy distribution and $\mathrm{U}_{O}>1$ corresponds to a topheavy distribution.

Figure 8. Drainage curves corresponding to finite liquid hold up in the films. The initial distribution of liquid in the Plateau borders is assumed to be uniform with height $\left(U_{0}=1\right)$.

Figure 9. Drainage curves accounting for film drainage kinetics. The parameter $F_{R}$ can be considered a ratio of the characteristic time required for flow through the Plateau borders divided by the characteristic time required for film drainage. Film drainage kinetics can be neglected when $\mathrm{F}_{\mathrm{R}}>10^{4}$. All gas-liquid interfaces are assumed to be rigid. 
Figure 10. Drainage curves accounting for film drainage kinetics. The parameter $F_{M}$ can be considered a ratio of the characteristic time required for flow through the Plateau borders divided by the characteristic time required for film drainage. Film drainage kinetics can be neglected when $F_{M}>10^{3}$. The gas-liquid interface of the Plateau border is assumed to be rigid and that of the film, mobile.

Figure 11. Schematic diagram showing how the cross section of the Plateau border varies with the contact angle at the film. 


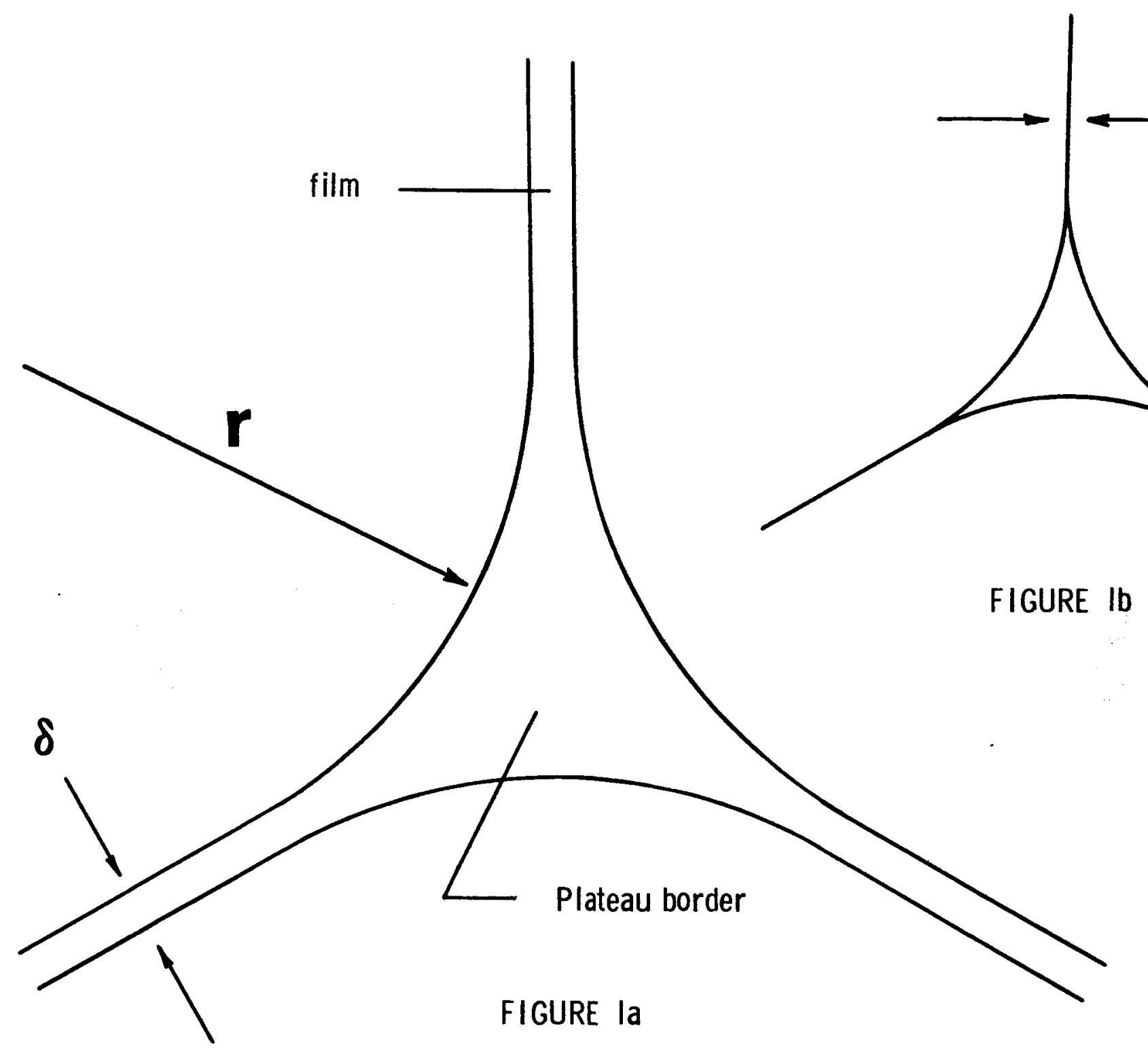




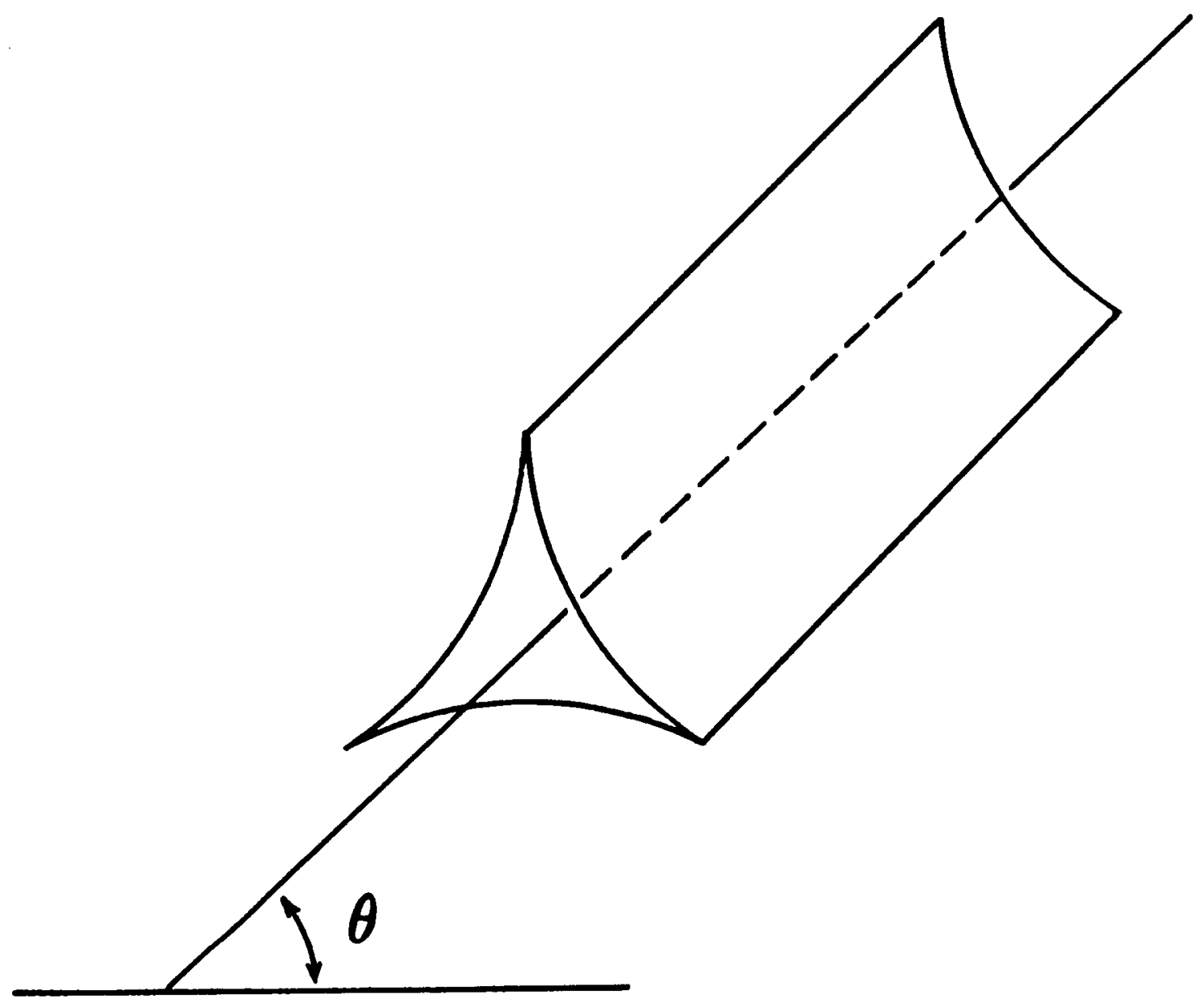

FIGURE 2 


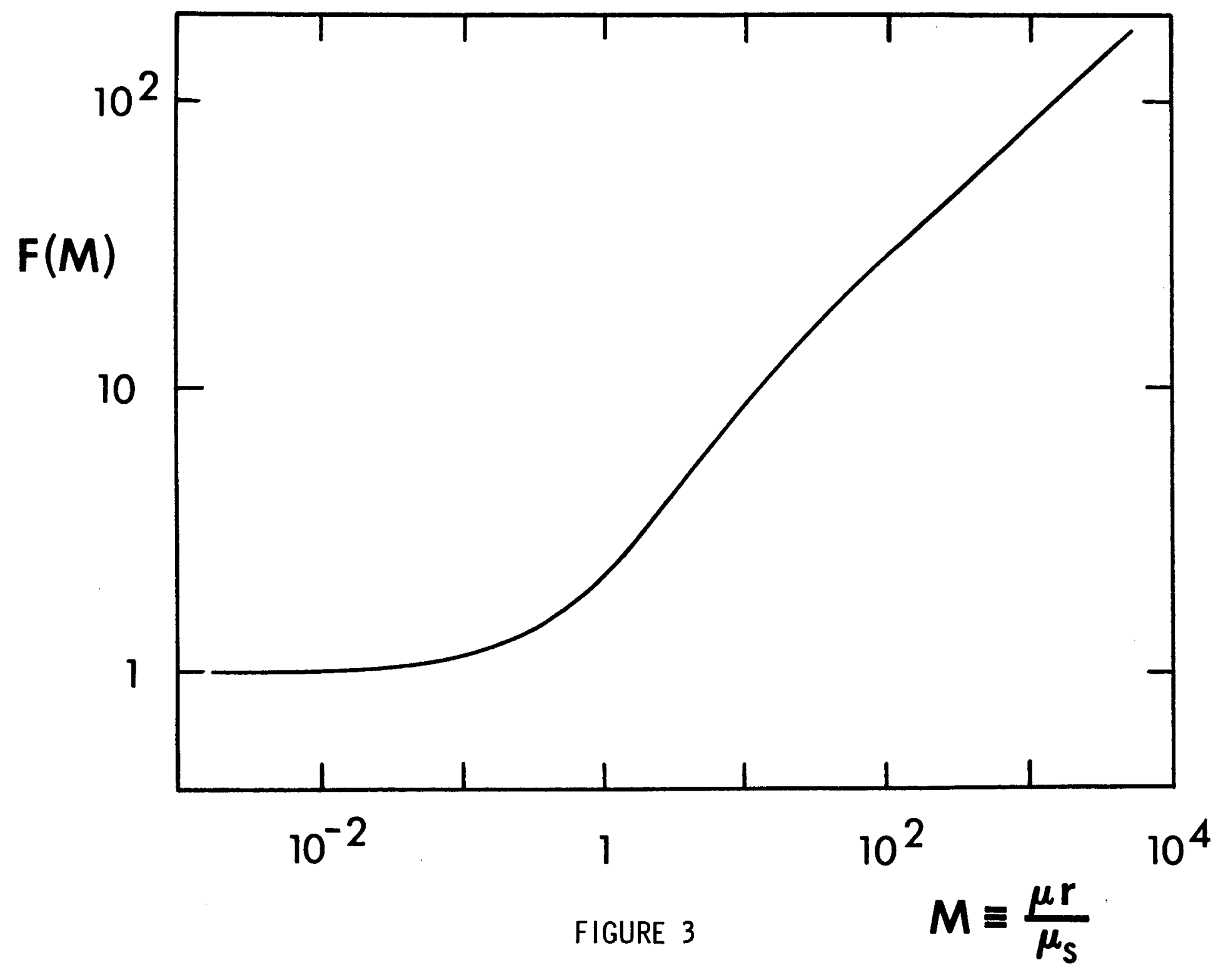




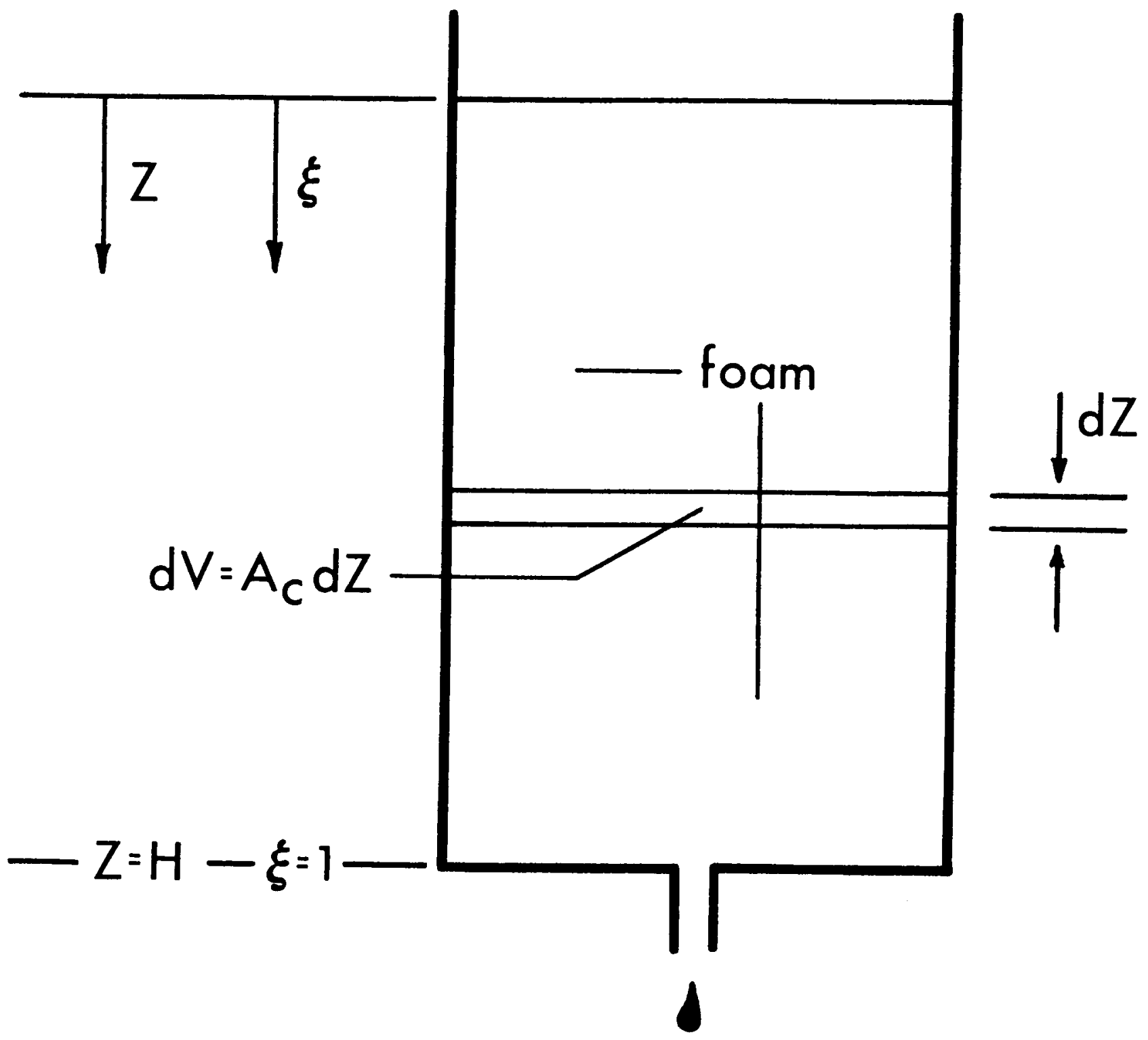

FIGURE 4 


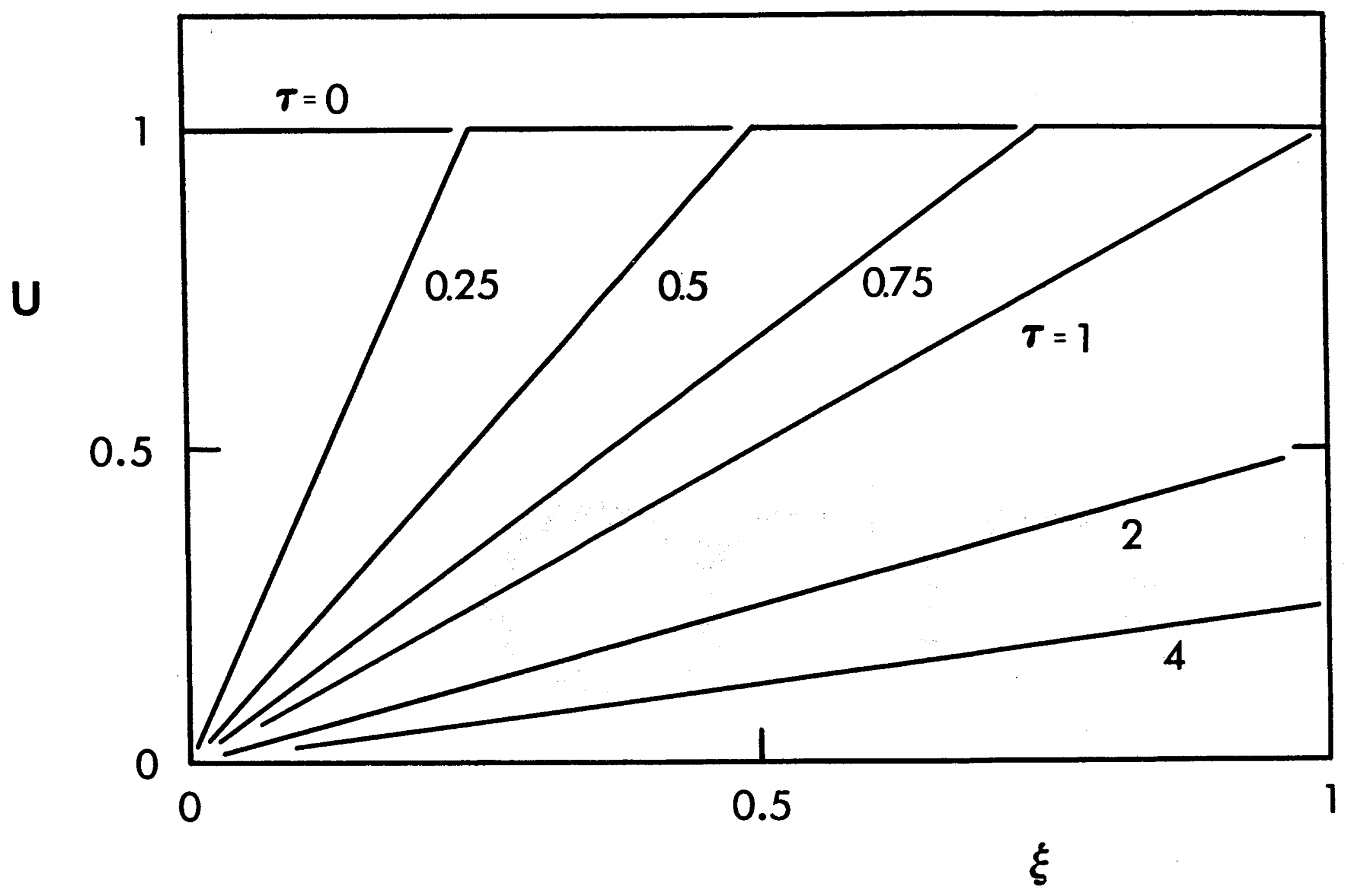

FIGURE 5 


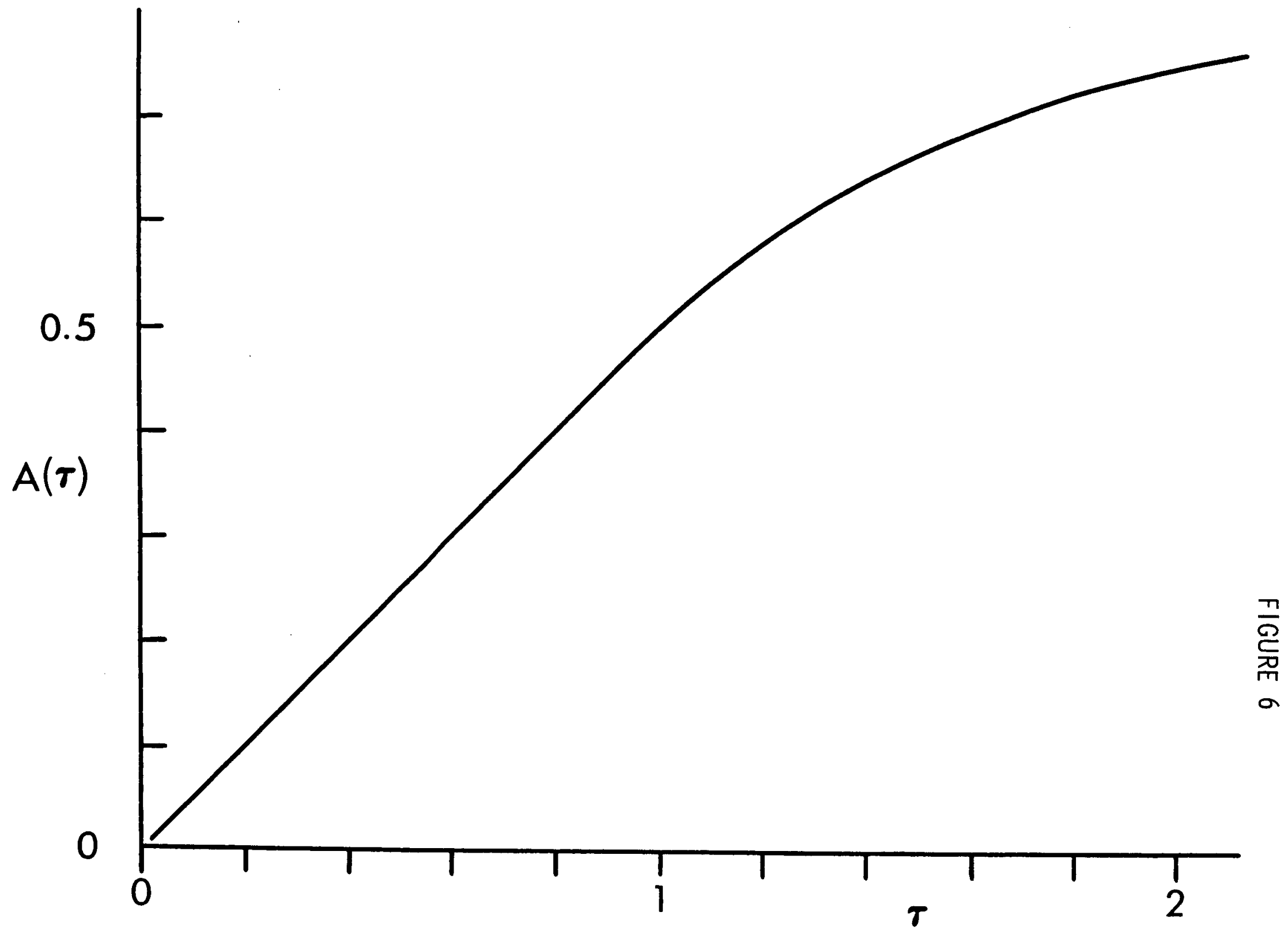




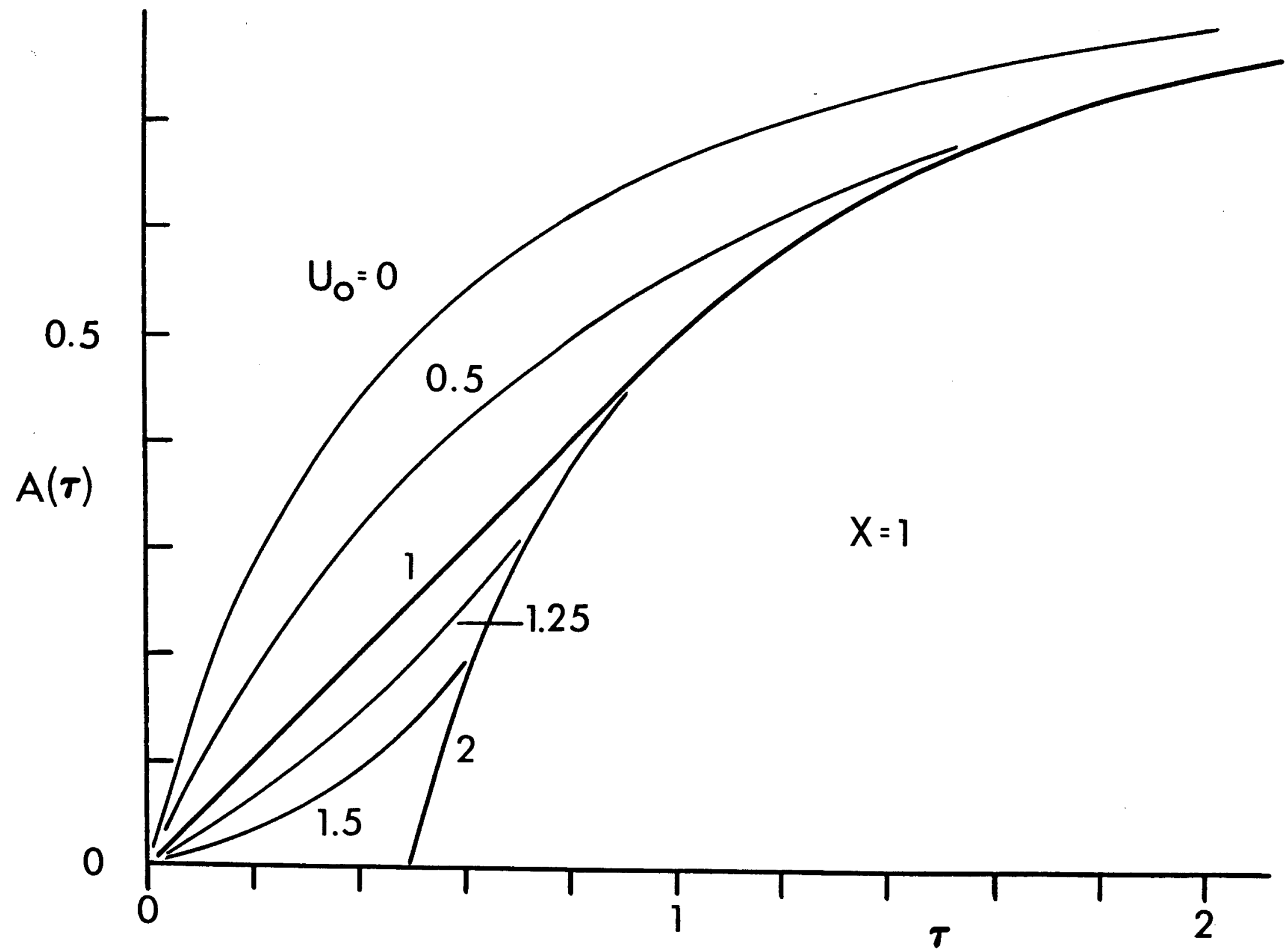

㟧 


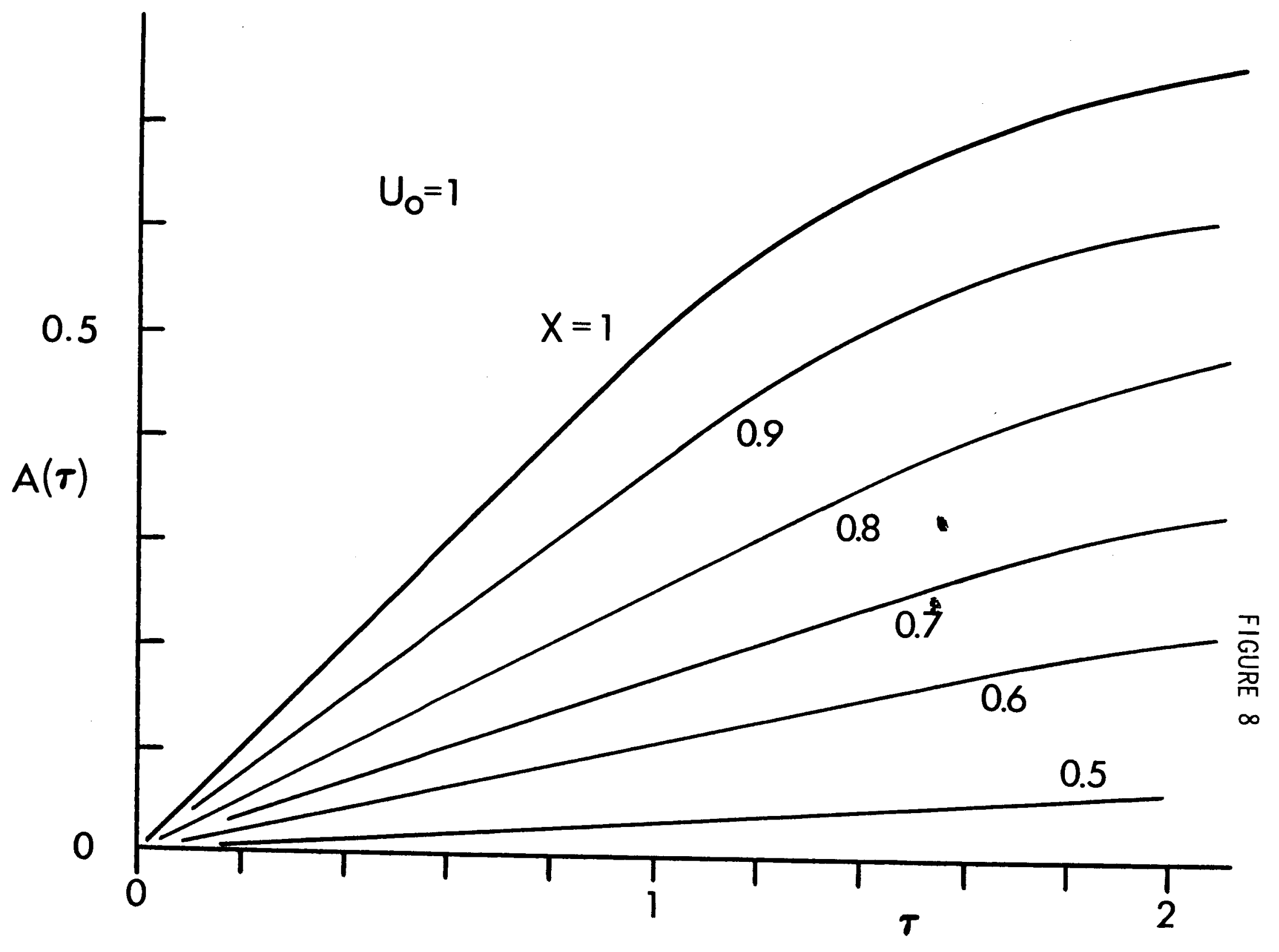




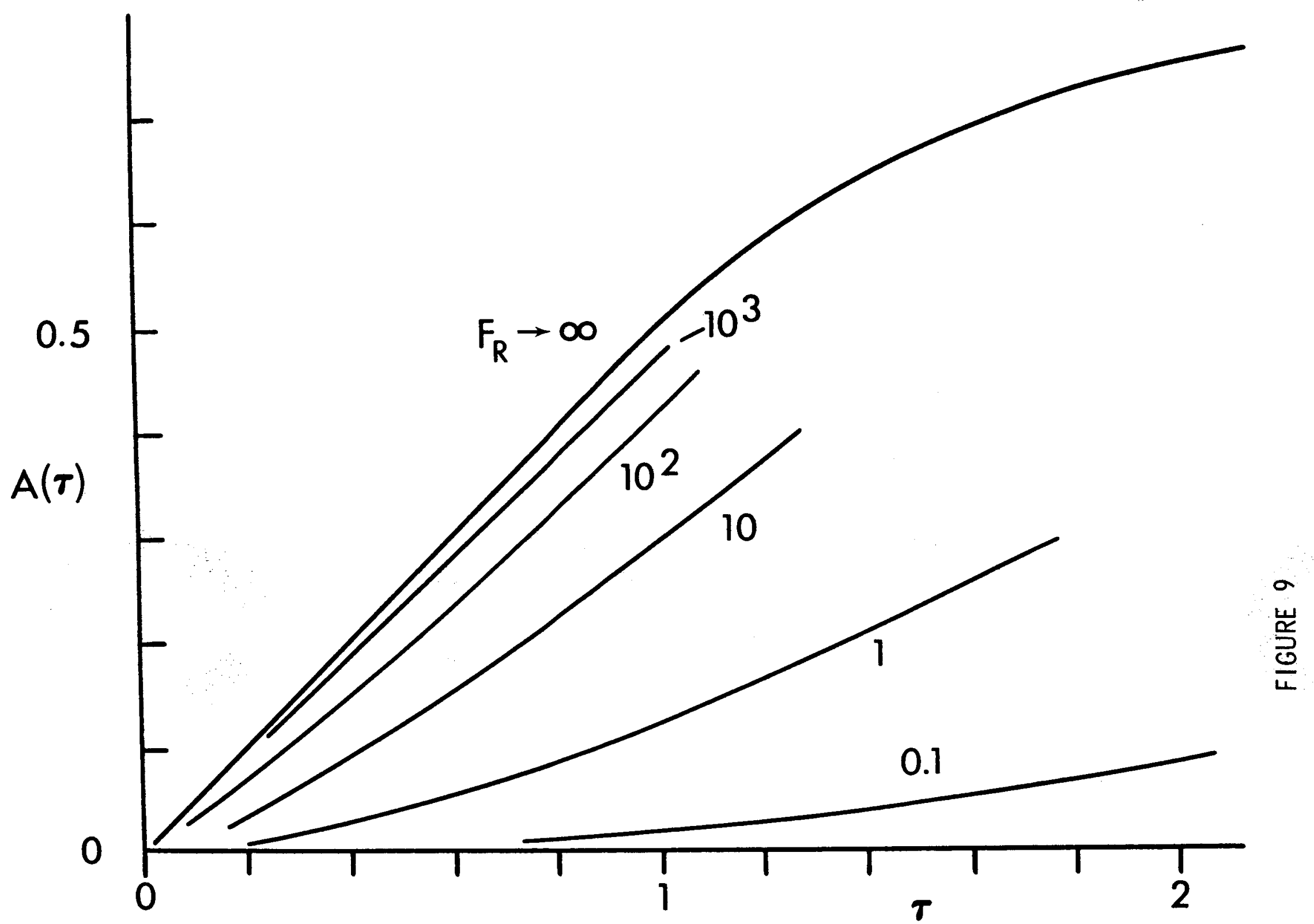




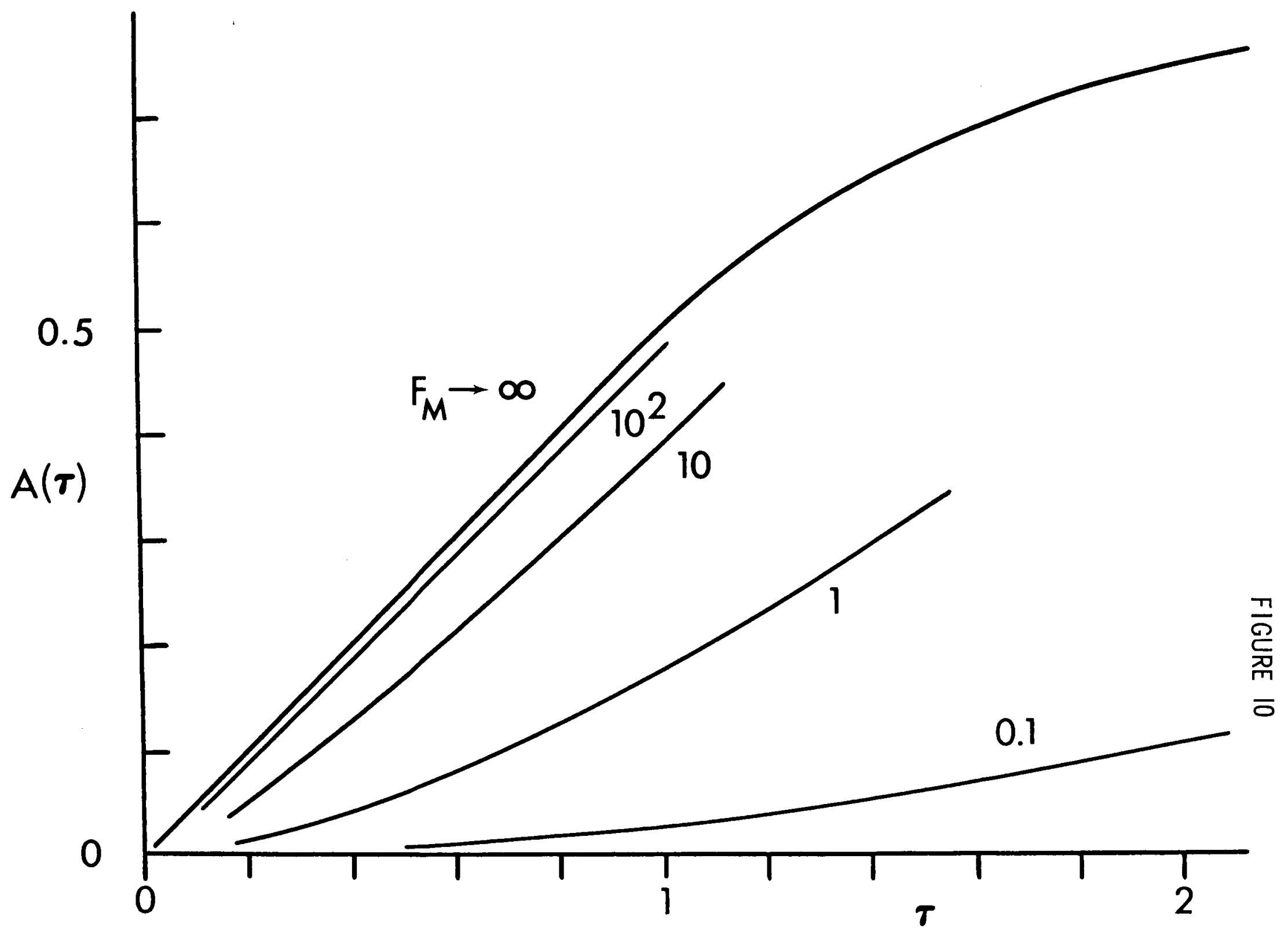




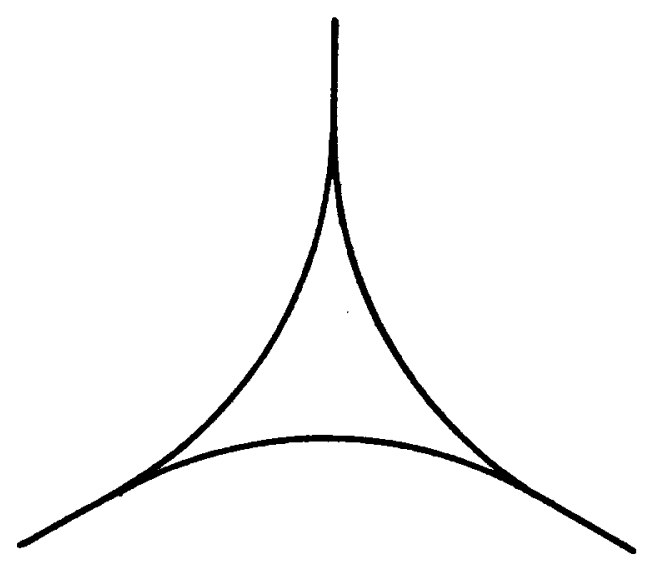

$\phi=0^{\circ}$

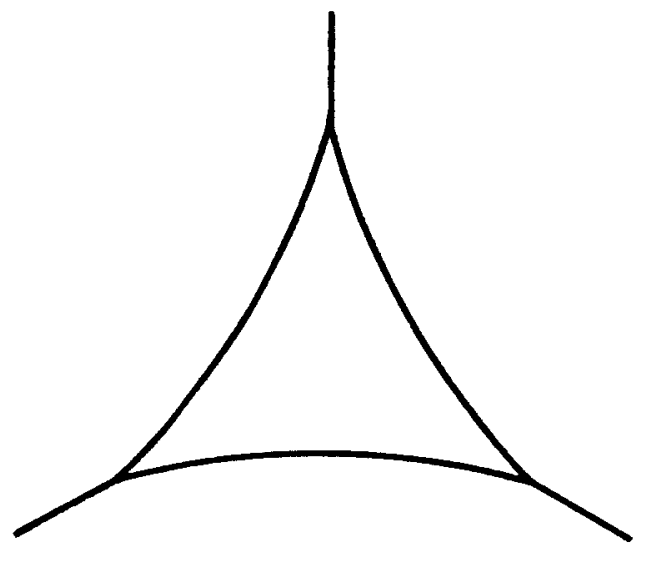

$0^{\circ}<\phi<30^{\circ}$

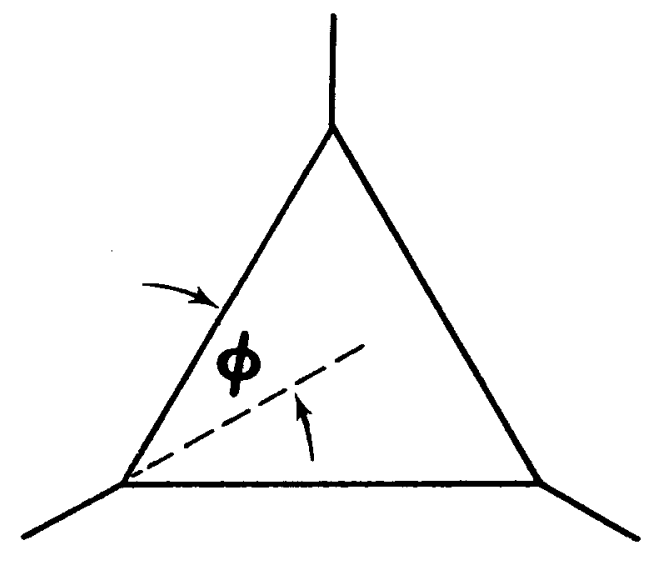

$\phi=30^{\circ}$

FIGURE II 
Distribution:

Dean Kavanagh

Monsanto Company

101 Granby Street

Bloomfield, Connecticut 06002

Richard Raspet

Construction Engineering

Research Lab

Department of the Army

Corps of Engineers

P. O. Box 4005

Champaign, Illinois 61820

Professor Robert Prud'homme

Department of Chemical

Engineering

Princeton University

Princeton, New Jersey 08540

Professor William B. Russell

Department of Chemical

Engineering

Princeton University

Princeton, New Jersey 08540

Professor Raymond Flumerfelt Department of Chemical

Engineering

University of Houston

Houston, Texas 77004

Lewis Norman

Halliburton Services

P. O. Box 1436

Duncan, Oklahoma 73536

Paul A. Haas

Oak Ridge National Laboratory

Bldg. 4505

P. O. Box X

Oak Ridge, Tennessee 37830

Professor Robert Armstrong

Department of Chemical

Engineering

Massachusetts Institute of Technology

Room 66-505

Cambridge, Massachusetts 02139

David Holcomb

Smith Energy Services

c/o Timbulane Bldg.

Junction Hwy. $58 \& 93$

Golden, CO 80403

Professor Robert Lemlich

Department of Chemical and

Nuclear Engineering

University of Cincinnati

Cincinnati, Ohio 45221

3151

3154-3 (25) for DOE/TIC

5200

5210

5211

5211

5250

5256

5256

5256

5256

6240

6241

6241

8424

(3)

W. C. Myre

G. H. Mauney

J. W. Kane

M. M. Plugge

T. A. Sellers

M. R. Madsen

L. A. Fjelseth

K. C. Goettsche

W. F. Hartman (5)

R. K. Traeger

J. R. Kelsey

C. C, Carson (10)

(1)

3141

(5) 
